\title{
Analysis of the dependence between the number of accidents at workplaces that involve scaffolding and changes in work efficiency
}

\author{
Marek Sawicki, Mariusz Szóstak* \\ ${ }^{1}$ Deparment of Construction Technology and Management, Faculty of Civil Engineering, Wroclaw \\ University of Science and Technology, 50-370 Wroclaw, Poland
}

\begin{abstract}
The purpose of the article is to present the occupational characteristics of people injured in accidents at workplaces that use construction scaffolding. The results obtained from the analysis of occupational accidents involving construction scaffolding, which took place in five Polish voivodships: Dolnoslaskie, Lubelskie, Lubuskie, Mazowieckie and Wielkopolskie between 2010-2015, were presented. 177 occupational accidents were analysed. On the basis of post-accident protocols, the following occupational characteristics of employees who suffered from accidents were identified: the age of the victim, the time of day when the accident happened and the season of the year. In turn, on the basis of a review of the subject literature, the course of changes in an employee's performance during the day, week and calendar year was determined. The relation between efficiency and the identified occupational characteristics of the injured parties was determined.
\end{abstract}

\section{Introduction}

The construction industry in Poland, as well as in the world, is characterized by a high level of hazard to the health and life of employees. Based on statistical data published by the Central Statistical Office of Poland in 2016, the number of all occupational accidents amounted to over 87,000, and 243 employees were killed in all sections of the economy. In turn, based on statistical data concerning the construction industry, it can be concluded that the Polish construction industry in 2016 was ranked in 8th place among all sections of the economy when considering the value of the accident rate [1]. The incidence rate of accidents for the construction industry amounted to 6.2 people injured per 1,000 employees. This value is lower than the value of the accident rate for all sections of the national economy, which in 2016 amounted to 7.0 people injured per 1,000 employees. According to the reports published by the National Labour Inspectorate, a fall from a height, especially a fall from scaffoldings, was the most common incompatible with the proper course of the work process event which caused the accident [2]. This article is the result of the research project "Model of the assessment of risk of the occurrence of building catastrophes, accidents, and dangerous events at workplaces with the use of scaffolding". Five team

* Corresponding author: mariusz.szostak@pwr.edu.pl 
consisting of employees of the Wroclaw University of Science and Technology, Lublin University of Technology and Lodz University of Technology conducted research in the Polish province. One of the research area of this project is research in the archives of national institutions concerning accidents at work on height.

Information on particular accidents, their circumstances and also their causes are included in Control Protocols, which are prepared by labour inspectors after an accident. The Control Protocol contains information on the time and place of an accident, the performed operations by the victim, the details of injured people, a description of the course of the incident that includes its circumstances and causes, information on the used materials and equipment of employees and also the assessment of post-accident proceedings with regards to the conclusions drawn after accidents, followed by preventive measures.

The purpose of the article is to present the occupational characteristics of people injured in occupational accidents at workplaces that use construction scaffolding. The authors have attempted to establish a relation between selected factors that characterize injured employees who work on scaffolding and a human's physiological parameters, which change with age.

\section{Literature survey}

The identification of an employee's personal characteristics that affect the accident rate in the construction industry is the subject of many researchers' analyses. Camino López et al. [3] conducted an analysis of 1,630,452 occupational accidents that occurred in the Spanish construction industry in the years 1990-2000. As a result of this analysis, 18 different factors that affect the accident rate were identified, such as: age, sex of an employee, type of contract with an employer, work experience, number of employees employed in a company, the type of company's activity, material factors related to an event, geographical location, etc.

López Arquillos et al. [4] in their conducted studies confirmed the dependence between the effects of an accident and the age of an injured person, type of business, size of company, work experience of the injured person, place of the accident, day of the week, number of days of absence of the injured person, injuries and also climatic zone.

The aim of the research conducted by Hola and Szostak [5] was to present the characteristics of people injured in occupational accidents in the Polish construction industry. The impact of the following features was identified and examined in the study: the status of the victim's employment, occupation, age, work experience, preparation of an employee to perform duties at the workplace and the size of the enterprise in which the accident occurred.

The analyses carried out by Drozd [6] concerned the indication of the importance of shaping a construction site and the behaviour of employees in defining the circumstances of an occupational accident. The author modelled the factors that determine the behaviour of construction workers during the execution of works and specified the following factors that characterize an injured person, namely: the population of employees - age, work experience; preventive activities - training; individual characteristics (behaviour) of employees - psychophysical condition.

Plebankiewicz et al. [7] found that the efficiency of employees is greatly influenced by: time spent out of work (appropriate length of rest, the impact of being absent), weather conditions (biometrics, temperature, humidity, extreme working conditions), employees' psychophysical condition (stress, fatigue, state of health, age), organization and management of an employee (work ergonomics, length of work shift, payment), as well as other factors such as the day of the week, experience and also adaptation to new working conditions or new technology. 
The size of the enterprise in which an accident took place, work experience and the age of a person injured in an occupational accident in the construction industry was the subject of analyses carried out by Chia-Fen et al. [8,9]. The study involved 411 fatal accidents that took place between 2001 and 2005 on construction sites in Taiwan. The researchers showed, among others, that $74.9 \%$ of all injured people had work experience of shorter than one year, and the largest number of people that suffer from accidents are aged between 35 and 44.

Saiful et al. [10] determined the relation between the number of fatalities and the age of a victim. On the basis of 90 fatal accidents that took place during construction works in Bangladesh, it was pointed out that employees aged between 26-41 were the largest group that undergo accidents and made up $68 \%$ of the victims.

According to Polek-Duraj [11], working conditions play an important role in every company. Improper working conditions (including excessive noise, poor lighting, poor work organization) have a negative impact on the functioning of an employee. The effect of harmful factors on the human body in the workplace causes many negative effects. The most frequently mentioned are the following: stress, fatigue, weariness, lower productivity of employees, occupational accidents and occupational diseases.

Wisniewski in 2009 [12] noted the relation between an employee's age and their performance, as well as the relation between an employee's experience and productivity. In European countries, the analyses that were carried out by Gelderblom and de Koning indicate that an employee reaches their maximum productivity at the age of 40-50. According to Crepon, the peak of an employee's productivity is noticeable at the age of 2534 , while the lowest efficiency is observed when an employee is over 50 years old. Gelderblom and de Koning noticed that up to the age of 50, an employee's productivity increases, and after exceeding 50 it considerably drops. Haegeland and Klette noticed a significant drop in the productivity of employees who had an experience of over 15 years [13].

Research carried out by O. Graf and G. Hildebrand [14] shows significant changes in the work efficiency of an employee during the course of a day. According to the daily work efficiency curve proposed by Otto Graf and presented in Figure 1, an employee achieves the highest work efficiency after 2.5 hours of work. After about 4 hours it decreases to reach a local minimum and increases until 5.5 hours. It reaches the daily minimum after 8 hours of work.

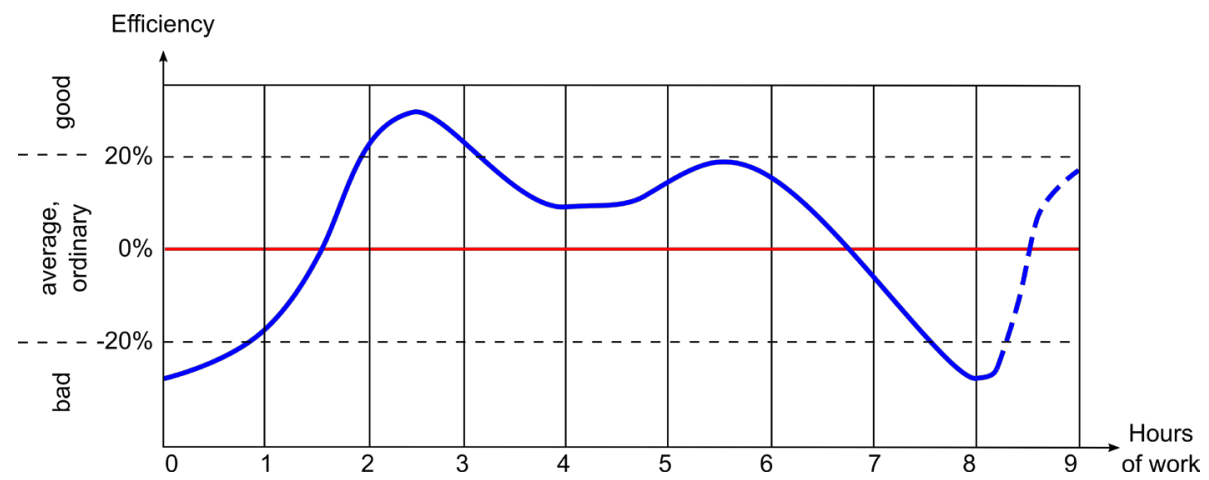

Fig. 1. Daytime work efficiency curve according to O. Graf [14]

In the circadian rhythm of the physical performance of the human body proposed by Hildebrandt and shown in Figure 2, an employee achieves their highest productivity between 8:00 a.m. and 10:00 a.m. Then at around noon, after 4 hours of work, the efficiency slowly decreases to a minimum. In the afternoon there is a new increase in 
efficiency, which does not, however, reach the level of before noon. After about 6 hours of work there is another decrease in efficiency until the end of the working day.

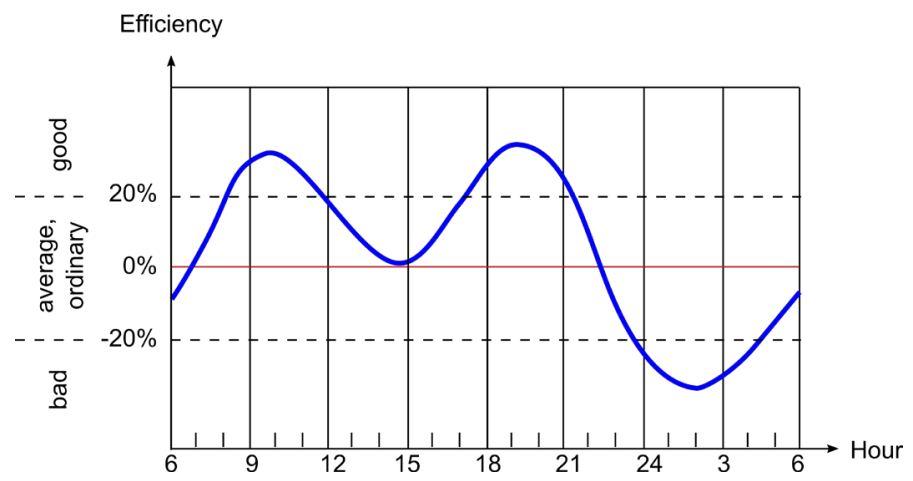

Fig. 2. The 24-hour rhythm of the human body's efficiency according to G. Hildebrandt [14]

It should also be noted that the performance of the human body also changes during the entire calendar year, as shown in Figure 3 [15].

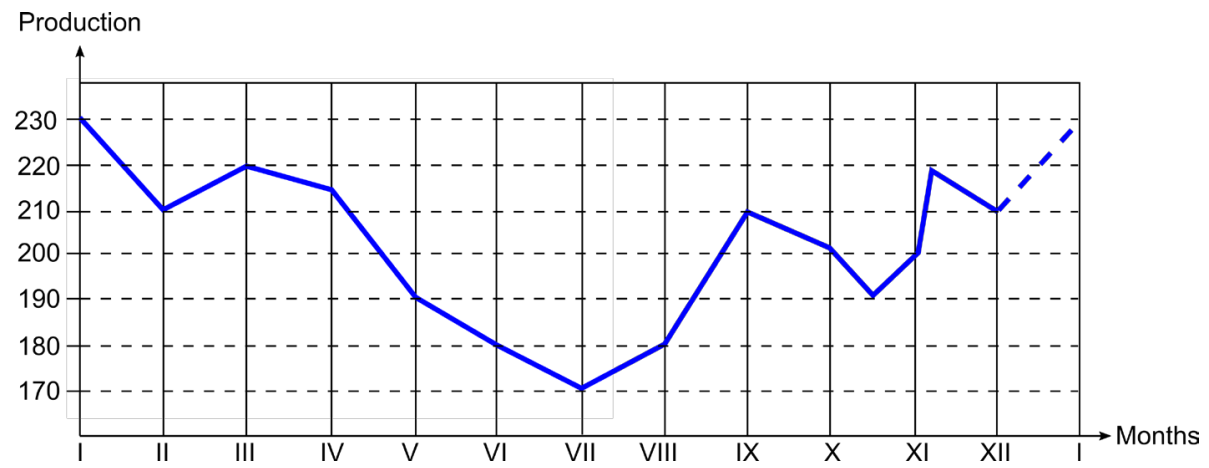

Fig. 3. Fluctuations in labour productivity during the calendar year [15].

The results presented above are largely influenced by the following physiological parameters of the body: the decrease in productivity associated with aging of the body and also the reduction of the so-called oxygen boundary - the ability to absorb oxygen by the body $[16,17]$. The decrease in the efficiency of an employee is related to the aging of the body, and thus a decrease in the heart rate. The decrease of the heart rate is caused by, among others, a reduction of heart efficiency and blood vessel capacity. The measure of human efficiency is the so-called oxygen boundary i.e. the ability of the body to absorb oxygen. The oxygen boundary reaches its highest values at the age of about 20 and then gradually decreases. In a man aged 40 , it reaches a value of around $80-90 \%$ of the maximum value. A person over 50 years of age reaches $70-80 \%$ of the maximum oxygen boundary, while this value falls to $60-70 \%$ for a person over 60 year old.

\section{Methodology of research}

The author's original methodology for defining the occupational profile of people injured in occupational accidents involving construction scaffolding was developed and consists of the following stages:

- stage I - the obtaining of post-accident examination protocols from the archives of the

National Labour Inspectorate, 
- stage II - the building of a database regarding occupational accidents,

- stage III - the identification of employees' professional characteristics,

- stage IV - the conducting of analysis.

Based on the post-accident protocols collected in Stage I, which were provided by District Labour Inspectorates in Poland and referred to occupational accidents in the construction industry which took place in the years 2008-2015 in five voivodships, a database was created in the second stage for occupational accidents at workplaces using scaffolding. The study involved 177 occupational accidents that took place in the Dolnoslaskie, Lubelskie, Lodzkie, Mazowieckie and Wielkopolskie voivodships.

In stage III, the following occupational characteristics of employees affected by accidents were identified, namely: the age of a victim, time of day at the time of an accident, or season.

In phase IV, an analysis of the collected data was conducted with regards to the individual professional characteristics of the employees injured in the investigated accidents in relation to the following changes in physiological parameters of a human, among others, employee's physiological changes during the day, week and subsequent months in the calendar year of work. In addition, correlations between the efficiency and identified occupational characteristics of injured parties were determined.

\section{Analysis of post-accident protocols}

In order to determine occupational characteristics, from the total number of post-accident protocols, documentation containing full information about the analysed feature was taken into account. Therefore, for some analyses, those accidents that did not have the analysed parameter were rejected. Thus, the research groups in the study of individual parameters were of different sizes.

\subsection{The number of accidents and the age of a victim}

The analysis of the age structure of people injured in occupational accidents at workplaces using construction scaffolding was carried out on a sample of 124 people. The reduction in the size of a tested sample is due to the fact that labour inspectors did not indicate detailed data about the age of 53 injured people.

The age structure of the victims is shown in Figure 4 and is as follows:

- the largest group of people injured in occupational accidents were people aged 46-50.

The number of people injured in this age group amounted to 23 people, and their share in the total number of victims amounted to $18.6 \%$,

- in second place is the group of people aged 36-40. The share of this group in the total number of injured people amounted to $15.3 \%$ and the number of victims is equal to 19 people,

- in third place is the group of people aged 51-55, which constituted $14.5 \%$ of all injured people.

- there is no visible trend of an increase or decrease in the number of accidents in relation to an employee's age. The disorder of the graph occurs for the 40-45 age range. 


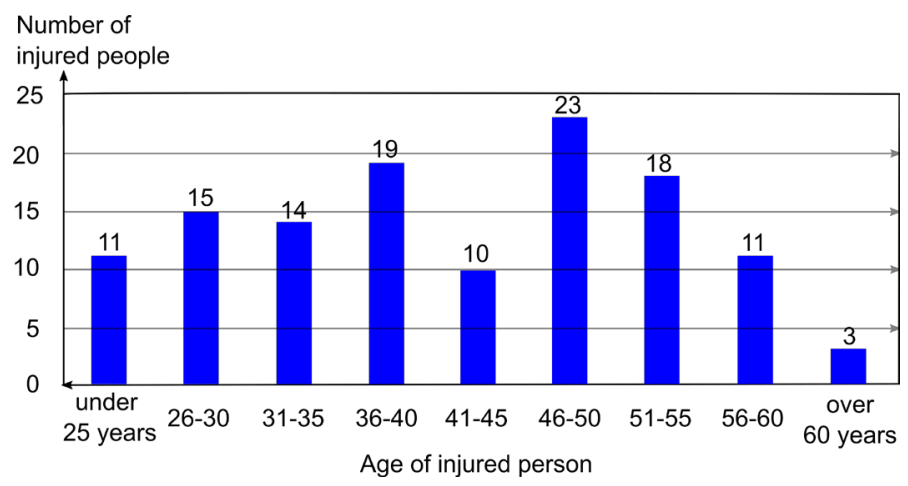

Fig. 4. Number of occupational accidents at workplaces that use construction scaffolding in relation to the age of the victim at the time of the accident

The number of people injured in the 40-45 age group, which amounted to 10 , was a surprise for the authors. On the basis of the analysis of literature, more people were injured in this group than in the case of employees aged 31-35, where the highest peak of productivity is noticeable. According to the authors, this is due, among others, to the fact that the population of workers of this age who were employed on construction sites was lower than for other groups.

Moreover, according to the authors, the largest number of accident incidents in the age range of 46-55 is related to the routine approach of employees to carried out professional activities (quite often having nearly 30 years of professional experience) and the reduction of psychomotor skills at this age. In the age group of over 56 years, a decrease in the number of accidental events is observed, which may be connected to a change in job position, retirement or being more secure at work.

\subsection{The number of accidents and the time of day}

The analysis of the time of the day of an occupational accident was carried out on a sample of 147 people. Figure 5 shows the number of occupational accidents in relation to the time of day.

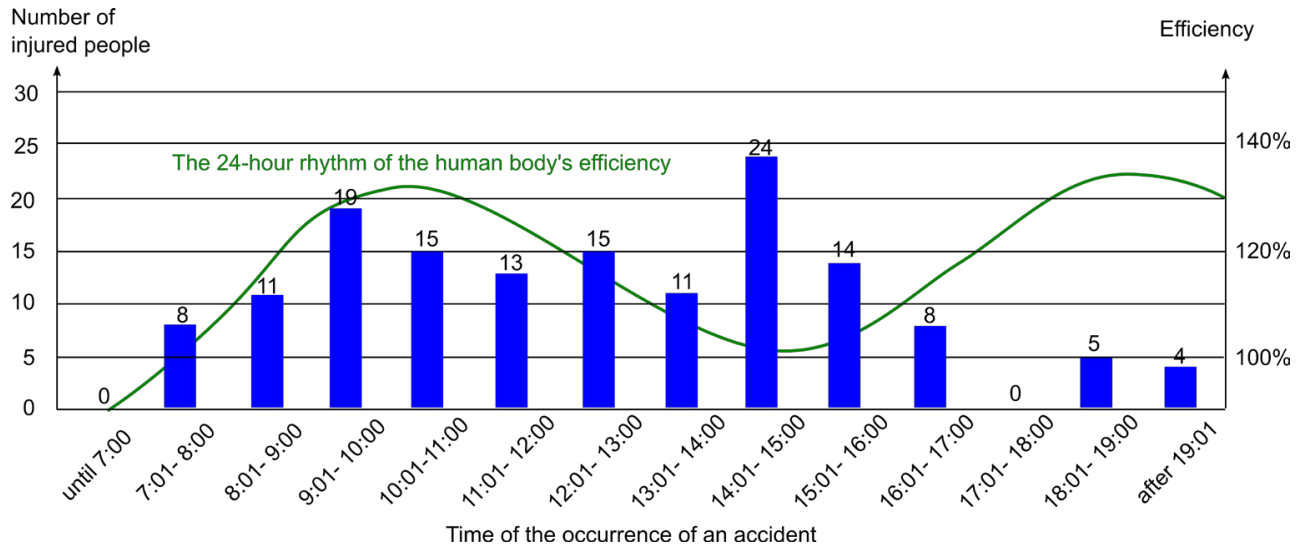

Fig. 5. Number of occupational accidents at workplaces that use construction scaffolding in relation to the time of day 
Analysis of the number of accidents with regards to the subsequent hours of work in which an accident occurred indicates that:

- the course of the distribution of accidents is of a wave nature,

- most accidents on scaffolding took place between 9:01 a.m. and 10:00 a.m. (the third hour of work) and between 2:01 p.m. and 3:00 p.m. (the seventh hour of work). This is before the breakfast break and before the end of an eight-hour shift, which is often the last hour of the working day,

- the highest number of accidents occurred between 2:01 p.m. and 3:00 p.m, at which time an employee achieves a local minimum of work efficiency,

- in the remaining time intervals, a decrease in the number of accidents is noticeable, which may be connected with the performance of tasks typical for the job performed by employees,

- working excessive hours (overtime, more than 8 hours a day) generates accident events, however, the trend shown in the chart is slightly disturbed because only some employees perform excessive work.

The authors of the article were not able to determine how many employees performed overtime work in companies in which the accident events occurred. The available publications show that employee efficiency, which is determined by the REFA curve (Work Research Commission) [1], increases during a work shift and reaches its maximum in the middle of the workday - between 11 a.m. and 12 p.m. It significantly decreases before the end of the workday i.e. before 3 p.m, and again reaches a maximum at around 5 p.m. It is of course important in this analysis to take into account the individual personal characteristics of an employee, such as age or individual character traits. The obtained data, shown in Figure 5, confirms the dependence between the number of accidents and the time of their occurrence.

\subsection{Age of a victim and the time of the occurrence of an accident}

The analysis of the age of a victim and the time when an occupational accident occurred at work posts that use construction scaffolding was carried out on a sample of 124 people. The previously presented dependencies related to human physiology allow the thesis that there is a close relation between the time of an accident and the age of a victim to be formulated. Figure 6 shows the age of a victim in relation to the time of day.

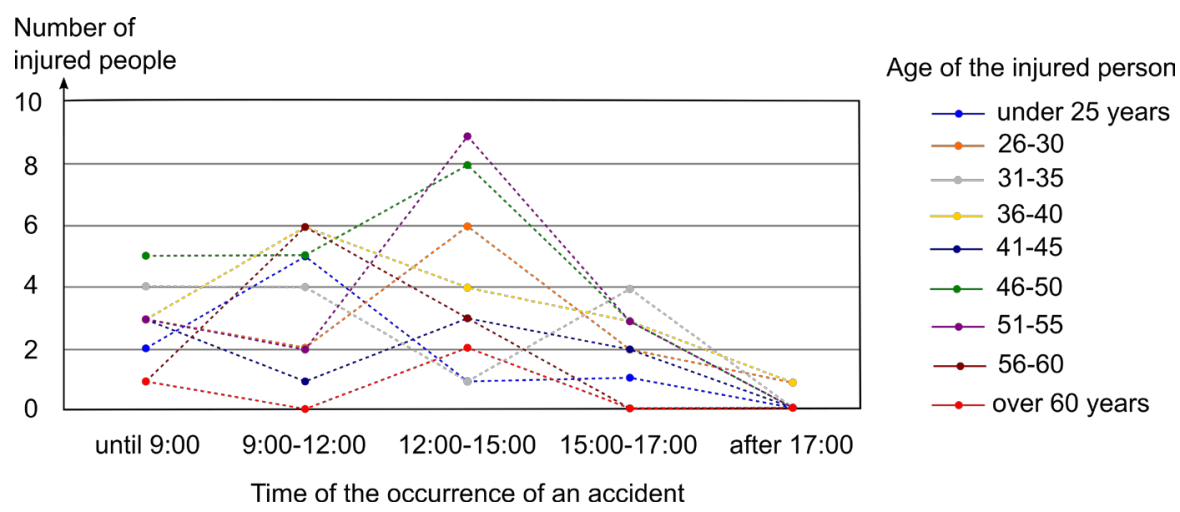

Fig. 6. Age of a victim and the time of an accident

The analysis of Figures 5 and 6 shows that:

- irrespective to the age group, most accidents occur between 9.00 a.m. and 12.00 p.m. and between 12.00 p.m. and 3.00 p.m., 
- the number of accidents that occurred until 9 a.m. in all age groups is equal to 19 and does not exceed 5 accidents in the case of employees aged 46-50 years, 4 accidents in the case of employees aged 31-35 years and 3 accidents in the case of other age groups (36-40 years, $51-55$ years or $41-45$ years),

- the number of accidents that occurred from 9.00 a.m. to 12.00 p.m. in most age groups slightly decreases or remains at a similar level, but also increases in the case of age groups of employees up to 25 years, 36-40 years and 51-55 years,

- there is no tendency of an increase in the number of accidents from 12 p.m. to 3 p.m. in the groups in which there was an increase between 9.00 a.m. and 12.00 p.m. Increments occur for other age groups and the largest is in the case of age groups of 51-55 years, 46-50 years and $26-30$ years,

- there is a decreasing tendency in the number of accidents from 3.00 p.m. to 5.00 p.m. and also after 5.00 p.m., except for the age group of 31-35 years for which it increases slightly,

- there was no straight dependency between the assessed factors for different age groups. However, a similar character of the accident occurrence curve during the subsequent hours of a work day, e.g. for the group of 26-30 years, 41-45 years, 46-50 years or over 60 years, is noticeable.

\subsection{Number of occupational accidents and the season of the year}

Analysis of the number of occupational accidents at workplaces that use construction scaffolding and the season of the year when an accident occurred was conducted on a sample of 129 people. Figure 7 shows the number of occupational accidents and the season of the year.

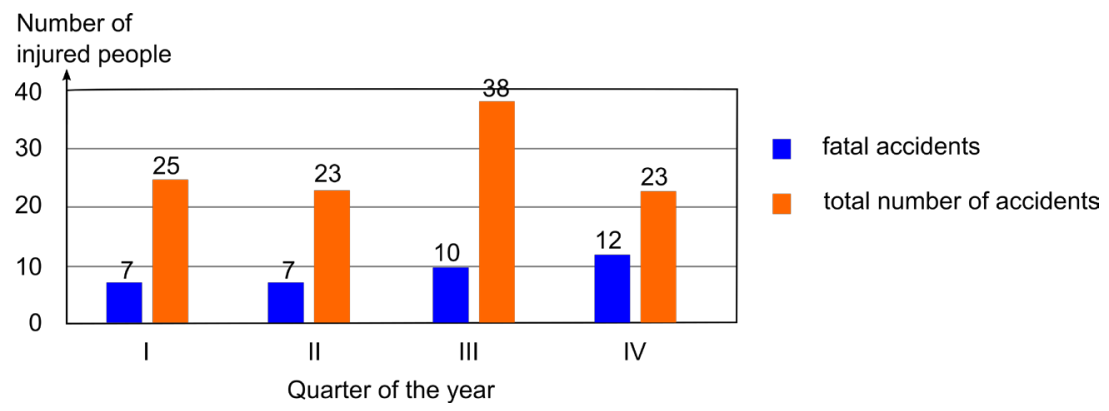

Fig. 7. The quarter of the year, fatal accidents and the total number of accidents

The number of occupational accidents at workplaces that use construction scaffolding depends largely on the so-called construction season, which peaks in the third quarter of the year. In the remaining quarters, the intensity of carried out works is slightly different. The reduced intensity of works is related to the occurring weather changes that adversely affect construction work on scaffolding. This is directly related to global warming and the very dynamic changes caused by weather anomalies such as intense storms, hurricanes or torrential rain.

A similar analysis carried out for fatal accidents shows a different character. They increase in subsequent quarters of the year and reach the maximum value in the fourth quarter. When comparing the results from Figure 7 with the results of the physiologists' research presented in Figure 3, the correlation between the change in the performance of the human body and the season is confirmed [14]. 


\section{Conclusions}

The literature review has shown that no occupational profile of people injured in accidents at work in construction industry as a result of falling from a height, especially from scaffoldings, has been developed so far. Analysis of people injured in occupational accidents involving construction scaffolding that took place in the construction industry in Poland in five voivodships in the years 2010-2015 allowed the following professional profile of an injured person to be formulated:

- parameters such as the age of a victim, the time of day of an accident and also the season when an accident occurred have a different impact on the number of accident events,

- the course of changes in the performance of employees is strongly influenced by age, as well as other factors such as the hour, time of day and quarter of the year,

- analysis of the age structure of injured people showed that the most common age group are people aged 46-50,

- people working in the afternoon between 2:01 p.m. and 3:00 p.m., at which time an employee achieves a local minimum of work productivity, are most often victims of accidents,

- analysis of the relation between the number of accidents and the time of year showed that the probability of an accident is the highest in the third quarter of the year.

The conducted data analysis and literature studies show the existence of a dependence between the accidents described in the protocols and the physiological parameters of the human body that change in subsequent periods of life. Of course, many factors depend on the working environment and the individual predispositions of a person. Therefore, according to the authors, the observed regularities allow actions that prevent accidents to be undertaken, which take into account the conclusions from this publication.

The article is the result of the implementation by the authors of the research project No. 244388 "Model of the assessment of risk of the occurrence of building catastrophes, accidents, and dangerous events at workplaces with the use of scaffolding", financed by NCBiR within the framework of the Program for Applied Research on the basis of contract No. PBS3/A2/19/2015.

\section{References}

1. Accidents at work. Central Statistical Office, Warsaw (2017)

2. A. Hoła, B. Hoła, M. Szóstak, IOP Conference Series: Materials Science and Enigneering, 251, 012050, 1-8 (2017)

3. M. A Camino López, D. O. Ritzel, I. Fontaneda, O. J. Gonzales Alcantara, Journal of Safety Research, 39, 497-507 (2008)

4. A. López Arquillos, J. C. Rubio Romero, A. Gibb, Journal of Safety Research, 43, (56), 381-388 (2012)

5. B. Hoła, M. Szóstak, Procedia Engineering, 208, 43-51 (2017)

6. W. Drozd, JCEEA, 63, 165-172 (2016)

7. E. Plebankiewicz, M. Juszczyk, J. Malara, Sci. Rev. Eng. Env., 65, 271-278 (2014)

8. C. Chia-Fen, C. Tin-Chang, T. Hsin-I, Applied Ergonomics, 36, (4), 391-400 (2005)

9. C. Chia-Fen, L. Syuan-Zin, R. S. Dewi, Accident Analysis \& Prevention, 72, 359-369 (2014)

10. I. M. Saiful, I. Razwanul, M. Tarek, Jordan Journal of Civil Engineering, 11, (2), $267-$ 278 (2017) 
11. K. Polek-Duraj, „Zeszyty naukowe” of the University of Economics in Katowice (in polish), 160, 151-159 (2013)

12. Z. Wiśniewski et al., Age management in organizations in relation to aging processes (in polish), (Dom Organizatora, Toruń, 2009)

13. Ageing and employment: Identification of good practice to increase job opportunities and maintain older workers in employment, European Commission, Munich (2006)

14. T. Dzierżykray-Rogalski, Rhythms and biological antirisms (in polish), (Wiedza Powszechna, Warszawa, 1986)

15. E. Kowal, The economic and social aspects of ergonomics (in polish), (PWN Scientific Publishing House, Warszawa-Poznań, 2002)

16. W. Z. Traczyk, A. Trzebski, Human physiology with elements of applied and clinical physiology (in polish), (PZWL Medical Publishing House, Warsaw, 2001)

17. J. Bullock, Physiology (in polish), (Urban\&Partner Medical Publishing House, Wroclaw, 2004) 